\title{
UMA ABORDAGEM SOBRE O PAPEL DAS REDES PARA PEQUENAS EMPRESAS E SOBRE OS EFEITOS NO APRENDIZADO DE EMPREENDEDORES
}

Pedro Henrique de Gois ${ }^{1}$

(PPA- UEM)

Hilka Pelizza Vier Machado²

(DAD/PPA-UEM)

Resumo: Este ensaio tem por objetivo identificar como a imersão em redes por empreendedores pode favorecer a aprendizagem para criação e desenvolvimento de pequenas empresas. Por meio da análise de estudos realizados na última década sobre o tema destaca-se a importância das redes para que empreendedores possam promover trocas de conhecimento e desenvolvam condições ao surgimento de informações visando à criação e identificação de oportunidades. A aprendizagem em empreendedorismo remete a busca de informações valiosas para assegurar o sucesso e a continuidade de pequenas e médias empresas em um mercado competitivo e dinâmico. Neste sentido, a aprendizagem empreendedora no contexto de redes sociais de relacionamento está ligada a um processo onde 0 empreendedor adquire conhecimento adequado para criar e gerir novos negócios (POLITIS, 2005). Estudos sobre a inserção de empreendedores em redes sociais (ARENIUS; CLERCQ, 2005; BAC; INCI, 2010; GREVE; SALAFF, 2003; KNIGHT, 2002) e sobre aprendizagem em empreendedorismo (COPE, 2005; CORBETT, 2007; HARRISON; LEITCH, 2005; POLITIS, 2005; ROWLEY, 2000) são apresentados como contribuições teóricas, nos quais se observa que 0 desenvolvimento da atividade empreendedora pode se ampliar por meio da troca de conhecimento, fator que implica no desenvolvimento do processo de aprendizagem em um ambiente de redes. Cabe ressaltar que a inovação e o desenvolvimento das pequenas empresas mereceram destaque entre os estudos, considerando 0 ambiente das redes de pequenos negócios, como as associações comerciais (MACHADO et al 2009) por exemplo, como forma de viabilizar o potencial empreendedor em muitos segmentos de mercado que estavam restritos por conta de infraestrutura e do conhecimento especializado necessários.

Palavras-chave: Aprendizagem, empreendedorismo, redes.

\footnotetext{
1 Correio eletrônico: pedrodgois@gmail.com. Endereço: Universidade Estadual de Maringá/Programa de Pós-Graduação em Administração (PPA/UEM), Avenida Colombo, 5790, Zona 7, Maringá, Paraná, CEP 87020-900.

2 Correio eletrônico: hilkavier@yahoo.com. Endereço: Universidade Estadual de Maringá, Centro de Estudos Socioeconômicos, Departamento de Administração. Avenida Colombo, 5790, Zona 7, Maringá, Paraná, CEP 87020-900.
} 


\title{
AN APPROACH ABOUT THE ROLE OF NETWORKS FOR SMALL BUSINESSES AND ABOUT THE EFFECTS ON THE ENTREPRENEURS LEARNING
}

\begin{abstract}
This article seeks to identify how the networks immersion by entrepreneurs can favor the learning for the creation and development of small businesses. Through the analysis of studies conducted over the last decade on the subject it is highlighted the importance of the networks for entrepreneurs to promote knowledge exchange and develop conditions to the emergence of information aiming at the opportunity creation and identification. The entrepreneurship learning refers to the search for valuable information to ensure the success and the continuity of small and medium businesses in a competitive and dynamic market. In this sense, entrepreneurial learning in the context of social networks of relationships is linked to a process where the entrepreneur acquires adequate knowledge to create and manage new business (POLITIS, 2005). Studies on the entrepreneurs inclusion in social networks (ARENIUS; CLERCQ, 2005; BAC; INCI, 2010; STRIKE; SALAFF, 2003; KNIGHT, 2002) and on the entrepreneurship learning (COPE, 2005; CORBETT, 2007; HARRISON, LEITCH, 2005; POLITIS, 2005; ROWLEY, 2000) are presented as theoretical contributions, in which it is observed that the development of entrepreneurial activity can be expanded through the knowledge exchange, a factor that involves the learning process development in a network environment. It should be noted that the innovation and the development of small enterprises stood out among the studies, considering the small business networks environment, such as the trade associations (MACHADO et al, 2009) for example as a way of enabling the entrepreneurial potential in many market segments that were restricted on account of the infrastructure and expertise required.
\end{abstract}

Key-words: Learning, entrepreneurship, network.

\section{INTRODUÇÃO}

Observar o desenvolvimento das atividades empreendedoras com base em redes exige, sobremaneira, reconsiderar de forma pontual a concepção do empreendedor enquanto indivíduo que age isoladamente e que detém todo o conhecimento necessário para se inserir no mercado. Os empreendedores, naturalmente, tendem a criar seus primeiros laços de trocas de informação entre aquelas pessoas que compõem seu círculo de convivência (família e amigos) antes da composição de redes amplas, para contato com outras pessoas através de estruturas formalmente organizadas.

A importância das redes para o desenvolvimento de pequenas e médias empresas (PMEs) a partir dos benefícios obtidos por meio destes mecanismos de agrupamento entre empreendedores e empresas é apontada por Havnes e Senneseth (2001). Sexton et al (1997) chamaram atenção para a necessidade de se 
compreender de que forma os mecanismos de aprendizagem pelo empreendedor são desenvolvidos, contribuindo para a criação de novos conhecimentos e desenvolvimento de habilidades, tanto individual como em redes.

Este artigo constitui um ensaio teórico acerca da imersão de empreendedores em rede, o que se justifica pelo potencial que estes relacionamentos trazem enquanto geração de oportunidades e criação de valor diferenciado em relação à atuação individualizada. O ensaio proposto traz à discussão a escolha pelos empreendedores de integrar redes em busca de melhores condições de aprendizagem ao se inserir em um ambiente de troca de informações e de apoio à exploração de novas oportunidades. O objetivo proposto é identificar como a imersão nestas redes de empreendedores pode favorecer a aprendizagem para criação e crescimento de pequenas empresas.

A aprendizagem empreendedora, num contexto de redes sociais de relacionamento, remete a um processo contínuo onde o empreendedor adquire conhecimento adequado para criar e gerir novos negócios (POLITIS, 2005). A busca de informações valiosas, tanto no nível relacional-pessoal quanto em redes, constitui um fator importante para o empreendedor, considerando aspectos de confiabilidade e de segurança no limiar do investimento em novas oportunidades que emergem dessas relações. Conforme Baron e Shane (2010) a confiança é um aspecto importante nos relacionamentos duradouros e próximos, sobre a qual se constroem laços de reciprocidade e trocas de informação entre os indivíduos que compõem uma rede.

$O$ processo de aprendizagem em redes representa um mecanismo de disseminação e amplificação de informações por empreendedores. As redes podem promover ou restringir o desenvolvimento de uma cultura empreendedora baseada em inovação e compartilhamento de conhecimento. As redes densas, compostas por empreendedores que mantém laços de proximidade, representam meios dinâmicos de circulação de conhecimento e ambientes de menor incerteza e ambiguidade sobre as informações (JULIEN, 2010).

Estudos sobre a inserção de empreendedores em redes sociais (BAC; $I N C l$, 2010; GREVE; SALAFF, 2003; ARENIUS; CLERCQ, 2005; KNIGHT, 2002) e sobre aprendizagem em empreendedorismo (POLITIS, 2005; HARRISON; LEITCH, 2005; COPE, 2005; ROWLEY, 2000; CORBETT, 2007), entre outros, surgem como discussões propondo avaliar o desenvolvimento da atividade empreendedora 
baseada em conhecimento e, portanto, no desenvolvimento do processo de aprendizagem em um ambiente de relacionamentos próximos e intensivos.

Tem-se em vista que a temática proposta busca contribuir no sentido de estender a abordagem conjunta das teorias de redes e empreendedorismo e, dessa forma, gerar conhecimento acerca da identificação, criação e desenvolvimento de novas oportunidades de negócios que podem se desenvolver sustentados no compartilhamento de conhecimento na rede.

A seguir, para compreensão do leitor, serão contextualizados os conceitos de redes e sua proximidade com o campo da aprendizagem no âmbito do empreendedorismo. Posteriormente, será apresentada a metodologia utilizada no estudo e a discussão proposta acerca do tema apresentado e as considerações finais.

\section{O PAPEL DAS REDES NO PROCESSO DE EMPREENDER}

Julien (2010) identificou que estudos sobre o nível de colaboração em uma rede, considerando o número de relações nela encontrado, indicam que há uma relação positiva entre a posição destes participantes e a inovação resultante de seus relacionamentos. A participação em redes, por outro lado, não é atributo que analisado isoladamente possa determinar ganhos e inovação, estando associada a fatores como intensidade nos relacionamentos e a confiança entre os atores. Neste estudo, o conceito de redes segue o que propõe Granovetter (1973) quando define as redes como relações frequentes, baseadas em um cenário de confiança entre os atores, tanto por meio de laços fortes, e relações esporádicas e diversificadas, como por meio de laços fracos.

A evidência de laços relacionais em redes muito densas ou onde se observa um restrito número de participantes pode tornar as trocas de informação pouco valiosas e redundantes entre si (GRANOVETTER, 1973). Outro aspecto apontado na literatura refere-se à capacidade de assimilar informações pelos participantes da rede. Conforme Bridge et al (2003) manter empresas pequenas é uma opção adotada por empreendedores que buscam atuar de forma localizada ou manter controle de suas atividades. Muitas vezes, o aprendizado para alguns participantes pode ser demasiado amplo para sua visão e expectativa inicial, superando sua capacidade de ação e expectativas iniciais e dessa forma interferindo na capacidade 
do empreendedor de agir sozinho ou de manter a sua pequena empresa em um nível que ele detenha total controle (JULIEN, 2010).

\subsection{O EMPREENDEDOR E A IMERSÃO EM REDES}

A evidência da participação dos empreendedores em ações conjuntas, através de parcerias e apoio mútuo, indica a necessidade de uma atenção à literatura sobre redes para melhor compreensão desta aproximação e seus resultados. Kimura et al (2006) afirmam que a área de estudos sobre redes vem se desenvolvendo no âmbito dos estudos acadêmicos, particularmente na área de pesquisa em Administração, com enfoque sobre a distribuição de recursos e o compartilhamento de experiência. A intensidade de relacionamentos nas redes sociais, reforçando o compartilhamento mútuo entre os agentes, está diretamente relacionada à coesão que permite que se forme um ambiente de confiança recíproca entre os indivíduos.

Bridge et al (2003) consideram que os relacionamentos interorganizacionais nos quais se inserem as pequenas empresas são processos desenvolvidos gradualmente, sendo sensíveis à percepção que as firmas têm entre si e considerando as necessidades e possibilidades que surgem a partir das redes. A formação de redes de empreendedores, neste sentido, representa a visualização de que valores compatíveis e os meios de ajuste e compromisso estão de acordo com os interesses dos membros da rede, envolvendo negociação e barganha através do estreitamento das relações, buscando dissipar a incerteza e consolidar um nível de confiança que assegure que a troca de conhecimento e o nível de aprendizagem estejam disponíveis, em condições de equilíbrio e acessibilidade entre os membros da rede.

A ação dos empreendedores com relação a sua integração a uma rede existente ou a formação de novas redes está relacionada a sua atuação, redefinindo condições de mercado existentes ou atuando em lacunas abertas por mudanças, identificando e explorando oportunidades (VALE el al, 2008). Para Parker (2008) os empreendedores, fundamentalmente, buscam aproximar relacionamentos, constituindo redes sociais, na busca de incentivos e no compartilhamento de informações entre os membros. O nível de informações que circula por uma rede também é variável, considerando a existência de conhecimento especializado que 
pode ser codificado e amplamente estendido pela rede e outro tipo de conhecimento ou informação, mais específico, que exige um relacionamento mais próximo, exigindo a construção de confiança por meio de contato forte e direto.

De acordo com Hoang e Antoncic (2003, p.168) para o campo do empreendedorismo "três elementos de rede emergem como críticos para pesquisa empírica e teórica: (1) a natureza do conteúdo que é trocado entre os atores; (2) os mecanismos de governança nos relacionamentos; e (3) a estrutura da rede criada para os relacionamentos entre os atores". A amplitude dos relacionamentos presentes na rede, com base nestes três aspectos delineia a qualidade dos relacionamentos, considerando o tipo de informação que se busca, qual a forma definida para que os recursos/informações sejam compartilhados e a estrutura dos níveis de proximidade e confiança existentes entre os empreendedores.

Além disso, O'Donnell et al (2001) demonstram a existência de uma variedade de configurações de redes entre pequenos empreendedores e consideram que poucas firmas de pequeno porte têm condição de atuarem sem algum grau de relacionamento interpessoal. Para eles, a diferenciação entre redes sociais (pessoal) e redes interorganizacionais (organizacional) parece apresentar uma sobreposição de conceitos quando trata de redes de pequenas empresas. Enquanto redes interorganizacionais têm sido tratadas como formas de rede vertical, em uma relação de cadeia com dependência complementar de recursos entre firmas de diferentes setores, redes horizontais vêm sendo identificadas entre empreendedores de um mesmo nível relacional, entre negócios do mesmo setor. No entanto, outras configurações de ações cooperativas são encontradas como a composição de distritos industriais, incubadoras, joint ventures, parcerias (KURATKO; HODGETTS, 2001) e arranjos produtivos (O'DONNELL et al, 2001).

A construção de um capital social em redes, composto por alto nível de confiança, admiração recíproca e identificação mútua, indica maior possibilidade de eficácia na realização dos propósitos definidos para o alcance de sucesso (BARON; SHANE, 2010). A aproximação dos empreendedores, formando redes para o desenvolvimento de relacionamentos representa um elemento chave para formação do capital social, tangível ou intangível, o que torna possível as empresas serem bem-sucedidas através de aspectos diferenciais únicos, a partir da sua capacidade de se apropriar de elementos da rede e reagrupá-los internamente, para se 
diferenciar e constituir vantagem competitiva no mercado em que atuam (GREVE; SALAFF, 2003).

Convém salientar que atingir um nível de confiança e admiração recíproca é difícil, como em casos em que se observa a concentração ou direcionamento no nível da rede e, ainda, em ocasiões em que se analisa a coordenação em redes densas (GINALSKI, 2011; BEUNZA; RUIZ, 2011). Bergh et al (2009) traçam um estudo avaliando a aprendizagem conjunta de empreendedores baseada na confiança entre os atores para exploração de oportunidades de negócios. O aspecto da confiança (BARON; SHANE, 2010; POLITIS, 2005) no estudo é fundamental para a consolidação da rede como um espaço seguro para que os empreendedores tenham condições de expor suas ideias e transparecer muitos aspectos de suas empresas de forma a buscar apoio e conhecimento para ampliar e desenvolver seus negócios.

Em síntese, a abordagem de redes compreende a conformação de estruturas de ajustamento entre agentes que consolidam uma estrutura de compartilhamento de informações e recursos de interesse mútuo (CROSS; ARMSTRONG, 2008). No âmbito do empreendedorismo, representa a constituição de uma estrutura que propicie benefícios mútuos entre pequenas empresas, fruto de trocas dinâmicas de informações, ajustamentos na obtenção de recursos e formação de conhecimentos.

\subsection{OS EMPREENDEDORES E OS PROCESSOS DE APRENDIZAGEM EM REDES}

As redes de relacionamento estabelecidas entre empreendedores podem representar meios de fortalecimento ou de limitação ao desenvolvimento de inovação e mudança. O aprendizado associado ao processo empreendedor relaciona ações desenvolvidas em contexto de mudança, onde aprender representa um continuum na criação e na manutenção das empresas (COPE, 2005).

Diversas abordagens sobre a aprendizagem por empreendedores vêm sendo desenvolvidas. Cope (2005) aponta três elementos que estão interconectados na formulação destes estudos: a) a natureza dinâmica do processo empreendedor baseada na concepção temporal de fases, para compreender como os empreendedores aprendem; b) processos inter-relacionados de aprendizagem, considerando 0 aspecto evolutivo das concepções aprendidas e; c) as características sociais de aprendizagem em que os empreendedores estão 
introduzidos. Cabe ressaltar que aspectos comportamentais contribuem para o processo de aprendizagem e na forma como o empreendedor vê a atividade que desenvolve, assim como no gerenciamento do negócio e, particularmente, contribui para compreender a busca por construir redes para consolidar contatos e buscar apoio para melhorar e sustentar seus negócios (COPE, 2005). Contudo, há que se considerar a influencia prévia do aprendizado do empreendedor, fruto de suas experiências a priori, da sua trajetória e das falhas decorrentes de tentativas anteriores de empreender, que se incorporam aos ganhos de relacionamentos externos por meio de redes.

Por exemplo, Politis (2005) menciona dimensões no processo de desenvolvimento de habilidades empreendedoras a partir de experiências em carreiras anteriores, considerando o know-how adquirido e a experiência específica em gestão em determinados segmentos. Outra característica é o processo de transformação, baseado na exploration (visualizando futuro, formas de agir e promover oportunidades potenciais) e exploitation (manipulação de uma bagagem de conhecimento, baseada em experiências passadas) como forma de reconhecer oportunidades e enfrentar as falhas de ações mal-sucedidas.

Além desses a aprendizagem com base na experiência criada por falhas passadas é analisada por Cope (2010) como uma característica que merece estudos mais detalhados, assim como o campo de estudos de aprendizagem pelos empreendedores de uma forma geral. A ação empreendedora, inserida em contexto de busca por resultados, cria mecanismos e estratégias que evitem erros e perdas. A falha, o fracasso ou perda de um investimento é um resultado indesejado e implica em aprendizado proveniente deste processo para os empreendedores que por ele passam. Aprender com as falhas representa uma das mais desafiadoras tarefas que o empreendedor pode enfrentar, emergindo desse processo aprendizado a ser revisto e sobre o qual o empreendedor constrói um repertório de informações valiosas para o desenvolvimento de ações preventivas no futuro ou, até mesmo, para explorar novas oportunidades (COPE, 2010; POLITIS, 2005).

Porém, a ação na forma conjunta permite uma aproximação entre os atores e a construção de conhecimento e hipóteses que podem ser extremamente úteis para o reconhecimento e desenvolvimento de oportunidades, dificilmente identificáveis por atores isolados. A ideia de aprendizagem conjunta conforme Taylor et al (2004) se fundamenta na segurança que o empreendedor identifica por meio da ação 
conjunta de aprendizagem, selecionando parceiros e um ambiente protegido para compartilhar informações e desenvolver ações de crescimento.

\subsection{VINCULAÇÃO DE REDES E DE PROCESSOS DE APRENDIZAGEM PARA O DESENVOLVIMENTO EMPREENDEDOR}

Muito além de duas áreas amplas de estudo e distantes entre si, a aprendizagem e a abordagem de redes constituem campos de estudo particularmente associados entre si, principalmente no processo relacional envolvendo empreendedores e suas experiências. Conforme Holcomb et al (2009, p. 172) "nós definimos aprendizagem empreendedora como o processo pelo qual as pessoas adquirem novos conhecimentos a partir de experiências diretas e a partir da observação de comportamentos, ações e consequências de outros". O modelo heurístico se insere nesta definição para delinear a forma pela qual o conhecimento anterior adquirido pode favorecer o desenvolvimento de novas descobertas e oportunidades para empreender, seja pela experiência própria ou por observação de outros indivíduos. O ganho ou o crescimento para os empreendedores, fruto do compartilhamento de experiências e informações, assim como de suas próprias ações e posicionamentos é fortalecido e favorece o desenvolvimento de novos negócios.

Quando se trata de redes e processos de aprendizagem o nível de análise a partir do empreendedor e das pequenas empresas novamente apresenta difícil delimitação entre redes sociais (indivíduos) e redes organizacionais (empreendimentos), sendo que o processo de aprendizagem também evidencia esta sobreposição entre o aprendizado e as experiências exclusivamente do indivíduo e aquelas que a organização criada pelo empreendedor desenvolve a partir de seus recursos, capacidades e das trocas através da relação com outras empresas (KNIGHT, 2002; HARRISON; LEITCH, 2005).

Processos de aprendizagem, pela sua conotação de continuidade e reavaliação constantes, podem ter outros desdobramentos de influencia sobre o empreendedor, que reflete e analisa a atividade que desenvolve tomando como referência, muitas vezes, sua experiência de vida (percepção de oportunidades) e, dessa forma, podem influir na formulação de ações e na identificação de oportunidades que dificilmente seriam visualizadas por outros indivíduos sem a 
mesma expertise e bagagem de experiências e conhecimento (HARRISON; LEITCH, 2005).

Por fim, a imersão em redes pode propiciar a criação, identificação e desenvolvimento de oportunidades pelo empreendedor (VAGHELY; JULIEN, 2010). Neste aspecto, o conhecimento, e como consequência os processos de aprendizagem, estão presentes e representam uma condição essencial para delimitar como as oportunidades surgem, como e em que condições determinados indivíduos (empreendedores) têm a capacidade de explorá-las e obter sucesso antes de outros.

Nesta perspectiva Ardichvili et al (2003) discutem a questão da oportunidade como um processo de desenvolvimento desta associada a traços pessoais do empreendedor e a redes de relacionamento próximo ou desenvolvido no decorrer da atividade empreendedora como forma de troca de informações e maior possibilidade de criação de novas oportunidades. Essas trocas contribuem para percepção de mudanças no mercado, que passam a demandar novos produtos e serviços, bem como por meio de assimetria de informação, onde o acesso a recursos ou a informação privilegiada coloca os indivíduos em condição de vantagem para explorar janelas diferenciadas que tendem a surgir no mercado (ECKHARDT; SHANE, 2003).

O papel da aprendizagem para a identificação e exploração de oportunidades é enfatizado por diversos autores como Shane (2000); Shane e Venkataraman (2000); Baron e Shane, 2010; Julien, 2010 e Vaghely e Julien, 2010, como forma de identificar os processos que envolvem o surgimento e a exploração destas oportunidades. Cabe destacar e trazer esta discussão para evidenciar que, dentre as diversas abordagens sobre oportunidades, a aprendizagem surge com destaque, mesmo entre aquelas abordagens que definem o reconhecimento de oportunidades como um processo cognitivo e focado no empreendedor.

A colaboração e parcerias que ocorrem em redes são potenciais mecanismos de aprendizagem, permeando a formação de um ambiente que proporcione melhor visualização de falhas ou deficiências nas rotinas e que contribui para o desenvolvimento de estratégias de atuação (TEECE et al, 1997). O desenvolvimento de abordagens buscando delinear esta aproximação entre empreendedores como forma de aperfeiçoar os processos de aprendizagem, em redes, demonstra ser, ao menos, uma possibilidade de compreender ações desenvolvidas individualmente e 
abertura a experiências e conhecimentos externos que podem potencializar a identificação de novas oportunidades de negócios.

\section{PROCEDIMENTOS METODOLÓGICOS}

Como afirma Davidsson (2004), os processos de relacionamento entre descoberta e exploração de novas oportunidades evocam questões centrais, como o que os indivíduos estão fazendo quando decidem iniciar, desenvolver e realizar ações que promovam novas atividades econômicas. Procurou-se compreender a ação empreendedora pela imersão em redes como forma diferencial de agregação de conhecimento e vantagens compartilhadas.

Para atingir o objetivo deste ensaio foi realizada uma pesquisa bibliográfica, na forma de estudo qualitativo, com estudos que abordaram a imersão de empreendedores em estruturas de cooperação e redes no campo do empreendedorismo.

Assim, foi realizado um levantamento de estudos dentre os principais journals e revistas da área de empreendedorismo (Entrepreneurship Theory and Practice, Journal of Small Business and Enterprise Development, International Small Business Journal, International Entrepreneurship Management Journal, Revista de Administração Contemporânea - RAC, Revista de Administração de Empresas RAE) e nos eventos nacionais EnANPAD e EGEPE, entre os anos de 2000 a 2010, selecionando publicações que abordam empreendedores e os resultados obtidos através das experiências pela integração e associação destes empreendedores em redes.

Conforme Bauer e Gaskell (2007), sugerem os dados foram agrupados em categorias a fim de relatar resultados do engajamento de empreendedores em redes buscando identificar como esta associação proporciona aprendizagem mútua entre os atores.

\section{ANÁLISE DOS DADOS: A PARTICIPAÇÃO EM REDES E APRENDIZADO EMPREENDEDOR}

Inicialmente, observou-se na literatura que o tempo é uma variável que influencia o aprendizado pelos empreendedores. Lévesque et al (2009) afirmam que o ato de está associado à reflexão de experiências passadas (HARRISON; LEITCH, 2005), no decorrer de fases de aprendizagem (COPE, 2005) ou pela experiência de 
outros empreendedores (POLITIS, 2005), influenciando na determinação do momento em que o empreendedor decide, objetivamente, colocar em prática uma oportunidade. A importância da aprendizagem também ocorre por meio de experiências de outros empreendedores, o que em determinadas indústrias se torna fundamental, ou seja, a relação com pessoas que já possuam conhecimento prévio das atividades e do mercado em específico (LÉVESQUE et al, 2009). A determinação do tempo de espera para empreender pode ser mais bem definida pela troca de informações e conhecimento, particularmente através de uma rede de interação com empreendedores experientes, diminuindo o tempo de aprendizagem e obtendo vantagem comparativa em relação a outros empreendedores (GREVE; SALAFF, 2003).

Grupos de empreendedores podem também se aproximar para criação de novos negócios (IACOBUCCI; ROSA, 2010). O agrupamento de empreendedores para os autores produz uma condição de conhecimento diferenciada, a partir da aprendizagem que emerge do corpo do grupo. O grupo cria sua própria identidade e desenvolve suas próprias capacidades, além da simples soma de experiências de cada indivíduo, delineando um ambiente favorável para o crescimento das pequenas empresas que se associam neste nível de colaboração. As chamadas equipes de empreendedores representam uma condição de análise sobre a aproximação de abordagens que levam em conta os recursos e capacidades pertencentes a determinadas empresas e o capital humano (e o aprendizado único inerente a esse ativo intangível) como forma de potencializar o desenvolvimento de novas oportunidades conjuntas, formando novos produtos, serviços ou empresas (IACOBUCCI; ROSA, 2010).

Dutta e Crossan (2005) consideram que os processos de aprendizagem pelos empreendedores se desenvolvem a partir do conhecimento econômico prévio em determinada área de produção, sendo um processo que acumula experiência e aprendizado no decorrer do ciclo de vida do negócio, bem como a partir da capacidade adquirida por meio do aprendizado gerencial e pelos resultados obtidos através do processo de construção social do conhecimento, que se processo em redes.

A aprendizagem em redes configura-se como um processo social (SIMON, 1991; DUTTA; CROSSAN, 2005) por meio de atividades individuais e de grupos internos, podendo abranger redes interorganizacionais. Outro efeito da imersão 
incide sobre as oportunidades, como já mencionado. Arenius e De Clercq (2005) afirmam que o potencial para identificar oportunidades está, em muito, associado às redes em que os empreendedores estão imersos, considerando que nas redes o capital humano é diverso e constituído por empreendedores com informações ricas e potenciais. As trocas tendem a se tornam frequentes e confiáveis, diferenciando o potencial de identificação e desenvolvimento da aprendizagem e, dessa forma, a exploração vantajosa de oportunidades. Nesse caso o potencial de conhecimento presente na rede é determinante para percepção e desenvolvimento de novos negócios.

No caso específico de empresas familiares, Zahra (2010) mostrou em estudo sobre o aprendizado em empreendimentos familiares, composto por uma amostra de 471 empresas familiares, a importância das redes de laços fortes proximais desenvolvidos entre os membros da família para dar sustentação e proporcionar um rápido aprendizado. A pesquisa mostrou que o conhecimento proveniente da aprendizagem contribui para construção e manutenção do sucesso da empresa familiar.

O processo de aprendizagem constitui processo de longo prazo, associado ao desenvolvimento da confiança mútua na rede, tendendo a se fortalecer e representar uma perspectiva de poder de reação dos membros da rede a situações que demandem respostas a mudanças sociais e de mercado e para exploração de novas oportunidades. A confiança, como se observa na literatura, difere em níveis e isso faz com que o processo de aprendizagem, neste sentido, varie entre os empreendedores em relação ao nível de desenvolvimento da confiança na rede. Níveis de confiança construídos com base no comprometimento, no companheirismo e nas competências observadas na rede proporcionam, crescentemente, a redução da incerteza e do risco de oportunismo e a mudança em aspectos sociais, emocionais e cognitivos entre os empreendedores que compõem a rede e, dessa forma, podem favorecer o reconhecimento e a exploração de oportunidades futuras (BERGH at al, 2009), como já mencionado.

Outro efeito da imersão em redes para as PMEs pode ser observado também quanto à capacidade de inovação. Por exemplo, Mello et al (2008) ao estudar o papel das redes de empreendedores no processo de inovação em pequenas e médias empresas. Mostraram que a formação de redes para colaboração e para promoção de processos de aprendizagem, através do compartilhamento de 
conhecimento e de desenvolvimento tecnológico, representa um importante mecanismo de apoio ao desenvolvimento e a formação de conhecimento rico, através do compartilhamento de informações, colaboração nos processos de pesquisa e desenvolvimento. Isso contribui para um posicionamento de PMEs num contexto competitivo, desencadeando um processo de articulação na rede para responder às mudanças de mercado e à melhor exploração dos segmentos em que as empresas atuam, através de investimento conjunto na construção de ferramentas e modelos adequados e inovadores.

A participação em redes, principalmente aquelas de laços fracos e diversificados mostrou-se importante para sobrevivência de pequenos negócios em estudo realizado por Vale e Guimarães (2010) com 178 empreendedores em níveis gerais, principalmente nos momentos iniciais da empresa e em momentos de instabilidade.

Finalmente, Borges Jr. (2004) demonstrou a importância da imersão em redes para a obtenção de diferenciais. A obtenção de informação por meio de participação em redes promoveu a participação de empreendedores em um ambiente propício à troca de informações (JULIEN, 2010).

Dessa forma, experiências compartilhadas em redes figuram como suporte para aprendizagem entre empreendedores (O'DONNELL, 2001). Mas, há que se ressaltar que esses efeitos são também dependentes da intensidade da participação na rede, como evidenciado por Machado et al (2009). A experiência trazida pelos empreendedores com maior idade e com vivência na rede, por exemplo, favorece o aprendizado e a disseminação de conhecimento, principalmente dentre aqueles participantes mais atuantes no nível da rede (HOLCOMB et al, 2009; POLITIS, 2005).

O quadro 1 sintetiza os estudos sobre a aprendizagem empreendedora por meio da participação em redes. 
Quadro 1 - Caracterização dos estudos eu relacionam empreendedores em redes e os processos de aprendizagem

\begin{tabular}{|c|c|}
\hline Autor (es) & Tipo de aprendizagem \\
\hline $\begin{array}{l}\text { HARRISON; LEITCH (2005); } \\
\text { POLITIS (2005); } \\
\text { LÉVESQUE et al (2009); }\end{array}$ & $\begin{array}{l}\text { Aprendizagem associada a experiências anteriores vivenciadas pelos próprios empreendedores e através de relatos/experiências } \\
\text { vividas por outros empreendedores, num processo que viabiliza ganho de tempo e conhecimento adequado para criação de novos } \\
\text { negócios. }\end{array}$ \\
\hline IACOBUCCI; ROSA (2010) & $\begin{array}{l}\text { As redes são analisadas como formação de grupos visando à intensa troca entre os membros para criação de novos produtos, serviços } \\
\text { ou novas empresas. O conhecimento e o aprendizado provenientes desta junção de forças visam potencializar a geração de } \\
\text { conhecimento valioso para seus membros. }\end{array}$ \\
\hline DUTTA; CROSSAN (2005) & $\begin{array}{l}\text { Aprendizagem como um processo desencadeado pelo conhecimento aplicado pelo empreendedor através das experiências acumuladas } \\
\text { no desenvolvimento de sua empresa, bem como através da aprendizagem socialmente estabelecida através de redes } \\
\text { interorganizacionais. }\end{array}$ \\
\hline ARENIUS; DE CLERCQ (2005) & $\begin{array}{l}\text { A identificação de oportunidades valiosas pelos empreendedores é estimulada através dos empreendedores em redes, considerando o } \\
\text { conhecimento amplo e diverso ali existente, assim como a capacidade de aprendizagem de cada empreendedor, que busca se } \\
\text { aperfeiçoar e desenvolver novas soluções/iniciativas através do conhecimento novo compartilhado. }\end{array}$ \\
\hline ZAHRA (2010) & $\begin{array}{l}\text { Destaque para a importância das redes de laços fortes, formada pela família e amigos, compreendendo um importante meio de troca } \\
\text { direta de informações e conhecimento, sendo o processo de aprendizagem imediato e rápido a que as empresas familiares têm a } \\
\text { disposição. }\end{array}$ \\
\hline BERGH et al (2009) & $\begin{array}{l}\text { Construção de confiança, através da formação de redes de empreendedores, para que a aprendizagem e o compartilhamento de } \\
\text { conhecimento possam circular, com segurança e qualidade, entre os membros associados. }\end{array}$ \\
\hline MELLO et al (2008) & $\begin{array}{l}\text { Redes empreendedoras para o desenvolvimento de inovação em pequenas empresas, muitas vezes com potencial subutilizado devido } \\
\text { às limitações estruturais e de conhecimento técnico especializado. A colaboração visa à construção de um ambiente de conhecimento } \\
\text { que proporcione condições para que os empreendedores possam superar suas dificuldades através do esforço conjunto. }\end{array}$ \\
\hline VALE e GUIMARÃES (2010) & $\begin{array}{l}\text { Imersão em redes empreendedoras como fator de sobrevivência de empresas. Os processos de aprendizagem através de redes, sejam } \\
\text { de laços fortes e fracos, representaram ser, significativamente, uma condição que viabiliza a criaçãa, o desenvolvimento e a } \\
\text { manutenção dos negócios no longo prazo. }\end{array}$ \\
\hline MACHADO et al (2009) & $\begin{array}{l}\text { Surgimento das associações comerciais como mecanismos de formação de redes de empreendedores para compartilhamento de } \\
\text { informações e aprendizagem, sendo uma experiência que demonstra ser importante para a identificação de oportunidades, } \\
\text { principalmente para os empreendedores mais atuantes na rede. }\end{array}$ \\
\hline BORGES Jr. (2004) & $\begin{array}{l}\text { A criação de redes de empreendedores é relacionada à criação de informações diferenciadas para o desenvolvimento de seus } \\
\text { membros, que destacam a confiança criada entre os membros da rede como fator diferenciado para criação de um conhecimento rico e } \\
\text { de amplo benefício a todos os participantes da rede. }\end{array}$ \\
\hline
\end{tabular}

Fonte: Os autores, com base nos dados analisados. 
Observou-se no quadro 1 que a formação de redes e a imersão dos empreendedores nestes ambientes proporcionam condições nas quais há troca de conhecimentos e experiências entre os membros, assim como a difusão de informações valiosas e, a partir delas, a consolidação de um conhecimento rico que proporciona a criação de novos produtos, serviços e, até mesmo, novas pequenas empresas. A inovação e a sobrevivência de pequenas empresas são influenciadas pelo ambiente de redes de pequenos negócios.

\section{CONSIDERAÇÕES FINAIS}

Neste estudo voltado a identificação de como a aprendizagem resulta da imersão de empreendedores em redes, observou-se que estas constituem espaços de disseminação de informações e de conhecimento entre empreendedores, por meio de compartilhamento de experiências individuais e contribuindo para um aprendizado a partir da relação grupal, para a identificação e desenvolvimento de oportunidades.

Benefícios da participação em redes para pequenas empresas e empreendedores são associados à criação e sobrevivência da empresa, melhoria na capacidade informacional e de identificação e exploração de oportunidades. Além disso, benefícios associados à inovação foram encontrados.

O desenvolvimento deste ensaio indica que o campo de estudos representa do empreendedorismo, redes e aprendizagem apresentam, entre si, complementaridades que demonstram ter potencial de desenvolvimento para ambas.

Para o empreendedorismo, compreender a formação de redes como forma de compartilhamento de conhecimento e criação de informações e, dessa forma, desencadeando processos de aprendizagem mútuos entre os membros da rede, pode fortalecer a inovação e a consolidação de áreas de negócios que demandam investimento e, sobretudo, necessitam de experiências e práticas que empreendedores têm condição de desenvolver, de uma melhor forma, associados em redes. Para a pesquisa em redes é possível identificar mecanismos de estímulo e aproveitamento do potencial inovador e criativo dos empreendedores, em 
diferentes áreas de negócios, para o desenvolvimento econômico e social como um todo, em diferentes regiões e países.

A limitação deste ensaio encontra-se no fato deste ter incluído publicações no campo do empreendedorismo e da administração e não ter abrangido as da sociologia econômica como forma de aprofundamento da abordagem de redes e de outras potenciais contribuições desta área de estudo para a aprendizagem por empreendedores.

\section{REFERÊNCIAS}

ARDICHVILI, A.; CARDOZO, R.; RAY, S. A theory of opportunity identitification and development opportunities. Journal of Business Venturing, v.18, p. 105-123, 2003.

ARENIUS, P.; CLERCQ, D. A Network-based Approach on Opportunity Recognition. Small Business Economics, v. 24, p. 249-265, fev. 2005

BAC, M. INCI, E. The Old-Boy Network and the Quality of Entrepreneurs. Journal of Economics \& Management Strategy, v. 4, n. 4, p. 889-918, 2010.

BARON, R. A.; SHANE, S. A. Empreendedorismo: uma visão do processo. São Paulo: Cengage Learning, 2010.

BAUER, M. W.; GASKELL, G. Pesquisa qualitativa com texto, imagem e som. Petrópolis, RJ: Vozes, 2007.

BERGH, P.; THORGREN, S.; WINCENT, J. Entrepreneurs learning together: The importance of building trust for learning and exploiting business opportunities. International Entrepreneurship and Management Journal, p.1-21, XX, 2009.

BEUNZA, J. M. I. Redes sociales y correspondencia epistolar. Del análisis cualitativo de las relaciones personales a la reconstrucción de redes egocentradas. REDESRevista hispana para el análisis de redes sociales, v. 21, n. 4, p. 98-138, 2011.

BORGES JR, C.V. Características e Contribuições das Redes para o Desenvolvimento das Pequenas e Médias Empresas. In: XXVIII Encontro Nacional 
da Associação Nacional de Pesquisa e Pós-Graduação em Administração ENANPAD. Anais... Curitiba-PR: set. de 2004. CD-ROM.

BRIDGE, S.; O'NEILL, K.; CROMIE, S. Understanding Enterprise,

Entrepreneurship and Small Business. Reino Unido: Palgrave Macmillan, 2003.

COPE, J. Toward a Dynamic Learning Perspective of Entrepreneurship.

Entrepreneurship Theory and Practice, v. 29, p. 373-397, Jul. 2005.

COPE, J. Entrepreneurial learning from failure: An interpretative phenomenological analysis. Journal of Business Venturing, p.1-20, XX, 2010. Disponível em: $<10.1016 /$ j.jbusvent.2010.06.002>. Acesso em: 03 dez. 2010.

CORBETT, A.C. Learning asymmetries and the discovery of entrepreneurial opportunities. Journal of Business Venturing, v. 22, p. 97-118, 2007.

CROSS, C.; ARMSTRONG, C. Understanding the Role of Networks in Collective Learning Processes: The Experiences of Women. Advances in Developing Human Resources, v. 10, p. 600-613, ago. 2008.

DAVIDSSON, P. Researching Entrepreneurship. New York: Springer, 2004.

DUTTA, D.K.; CROSSAN, M.M. The Nature of Entrepreneurial Opportunities: Understanding the Process Using the $4 \mathrm{I}$ Organizational Learning Framework. Entrepreneurship Theory and Practice, v. 29, p. 425-449, 2005.

ECKHARDT, J. T.; SHANE, S. A. Opportunities and Entrepreneurship. Journal of Management, v. 29, p. 333-349, 2003.

GINALSKI, S. Las empresas familiares en la red inter-firmas: el caso de la industria suiza de máquinas y metales en el siglo XX. REDES- Revista hispana para el análisis de redes sociales, v. 21, n. 9, p. 453-494, 2011.

GRANOVETTER, M. The strength of weak ties. American Journal of Sociology, v. 78, p. $1360-1380,1973$. Disponível em: 
http://www.stanford.edu/dept/soc/people/mgranovetter/documents/granstrengt hweakties.pdf>. Acesso em: 04 dez. 2010.

GREVE, A.; SALAFF, J. W. Social Networks and Entrepreneurship.

Entrepreneurship Theory and Practice, v. 28, p. 1-22, set. 2003.

HARRISON, R. T.; LEITCH, C. M. Entrepreneurial Learning: Researching the Interface Between Learning and the Entrepreneurial Context. Entrepreneurship Theory and Practice, v. 29, p. 351-371, jul. 2005.

HAVNES, P.; SENNESETH, K. A Panel Study of Firm Growth among SMEs in Networks. Small Business Economics, v. 16, p. 293-302, 2001.

HOANG, H.; ANTONCIC, B. Network-based research in entrepreneurship A critical review. Journal of Business Venturing, v.18, p. 165-187, 2003.

HOLCOMB, T. R.; IRELAND, R. D.; HOLMES JR, R. M.; HITT, M. A. Architecture of Entrepreneurial Learning: Exploring the Link Among Heuristics, Knowledge, and Action. Entrepreneurship Theory and Practice, v. 33, p. 167-192, 2009.

IACOBUCCI, D.; ROSA, P. The Growth of Business Groups by Habitual Entrepreneurs: The Role of Entrepreneurial Teams. Entrepreneurship Theory and Practice, v. 34, p. 351-377, 2010.

JULIEN, P. Empreendedorismo regional e a economia do conhecimento. São Paulo: Saraiva, 2010.

KIMURA, H.; TEIXEIRA, M. L. M.; GODOY, A. S. Redes Sociais, Valores e Competências: Simulação de Conexões. Revista de Administração de Empresas - RAE. São Paulo, v. 46, p. 42-57, 2006.

KNIGHT, L. Network learning: Exploring learning by interorganizational networks. 55; Human Relations, v. 55, p427-454, 2002. 
KURATKO, D. F.; HODGETTS, R M. Entrepreneurship: A Contemporary Approach. Orlando: Harcourt College publishers, 2001.

LÉVESQUE, Moren. MINNITI, Maria. SHEPHERD, Dean. Entrepreneurs' Decisions on Timing of Entry: Learning From Participation and From the Experiences of Others. Entrepreneurship Theory and Practice, v. 33, p. 547-570, 2009.

MACHADO, H. V.; SILVA, T.; NASCIMENTO, M. R. Empreendedorismo e Redes: a exploração de oportunidades em Associações Comerciais. In: XXXIII Encontro Nacional da Associação Nacional de Pesquisa e Pós-Graduação em Administração ENANPAD. Anais... São Paulo-SP, set. 2009. CD-ROM.

MELLO, C.; JESUS, M. J. F.; MACHADO, H. P. V. Inovação em PMEs O Papel das Redes e do Empreendedor. In: V Encontro de Estudos Sobre Empreendedorismo e Gestão de Pequenas Empresas - EGEPE. Anais... São Paulo, mar. 2008. CD-ROM.

O'DONNELL, A.; GILMORE, A.; CUMMINS, D.; CARSON, D. The network construct in entrepreneurship research: a review and critique. Journal of Small Business and Enterprise Development, v. 39, p. 749-760, 2001.

PARKER, S. C. The economics of formal business networks. Journal of Business Venturing, v. 23, p. 627-640, 2008.

POLITIS, D. The Process of Entrepreneurial Learning: A conceptual Framework. Entrepreneurship Theory and Practice, v. 29, p. 399-424, jul. 2005.

ROWLEY, J. From learning organization to knowledge entrepreneur. Journal of Knowledge Management, v. 4, p. 7-15, 2000.

SEXTON, D. L.; UPTON, N. B.; WACHOLTZ, L. E.; MCDOUGALL, P. P. Learning needs of Growth-oriented entrepreneurs. Journal of Business Venturing, v. 12, p.1-8, 1997.

SHANE, S. Prior knowledge and the discovery of entrepreneurial opportunities.

Organization Science, v. 11, p. 448-469, 2000. 
SHANE, S. VENKATARAMAN, S. The promise of entrepreneurship as a field of research. Academy of Management Review, v. 25, p. 217-226, 2000.

SIMON, H. A. Bounded rationality and organizational learning. Organization Science, v. 2, p. 125-134, 1991.

TAYLOR, D. W.; JONES, O.; BOLES, K. Building social capital through action learning: an insight into the entrepreneur. Education + Training, v. 46, p.226-235, 2004.

TEECE, D. J.; PISANO, G.; SHUEN, A.; Dynamic Capabilities and Strategic Management. Strategic Management Journal, v.18, p. 509-533, ago. 1997.

VAGHELY, I. P.; JULIEN, P. Are opportunities recognized or constructed An information perspective of entrepreneurial opportunity identification. Journal of Business Venturing, v. 25, p. 73-86, 2010.

VALE, G. M. V.; GUIMARÃES, L. O. Redes sociais na criação e mortalidade de empresas. Revista de Administração de Empresas - ERA, São Paulo, v. 50, p. 325-337, 2010.

VALE, G. M. V.; WILINSON, J.; AMÂNCIO, R. Empreendedorismo, Inovação e Redes: uma nova abordagem. Revista de Administração de Empresas - ERA Eletrônica, v. 5, p. 1-16, 2008. Disponível em:

<http://www16.fgv.br/rae/rae/index.cfm >. Acesso em: 02 dez. 2010.

ZAHRA, S. A. Organizational learning and entrepreneurship in family firms: exploring the moderating effect of ownership and cohesion. Small Business Economics, p. 115, XX, 2010. 